\title{
ASSESSMENT, ANALYSIS AND STUDY OF ENCROACHMENTS AND CHANGE IN NATURAL WATER FLOW IN INTERIORS OF WORLD FAMOUS DAL LAKE DURING 2003 -2015.
}

\author{
Moazam Iqbal ${ }^{1}$ \\ ${ }^{1}$ Student, Department of Civil Engineering, DIT University, Dehradun, Uttarakhand, India
}

\begin{abstract}
Advancements in study and assessment of changing land use patterns using modern techniques like use of satellite data is inevitable today owing to high accuracy and ease of its accessibility to researchers. In this study, satellite images of over last ten years have been precisely used to analyze the changes in natural water flow and geographic characteristics of world famous Dal Lake in state of Jатти \& Kashmir arising due uncontrolled human expansion and destruction of natural lake topography. The lake currently in advanced stages of eutrophication has been rapidly shrinking in its area at an alarming rate over last five decades. Major contributors to such changes are the direct or indirect discharge of untreated wastes from Srinagar city into water body through numerous sewer lines and uncontrolled land filling by local inhabitants in interiors of lake to meet their growing needs of urbanization and need for more agricultural land. Nutrients such as phosphorus and nitrogen derived from growth of vegetation within the lake and sewage have drastically altered water quality parameters and dramatically disrupted the Biological Oxygen Demand (BOD) of lake from years; making the water obtained from lake unfit for any kind of consumption or aquatic life. Uncontrolled pollution and wide encroachments laden with exponential increase of sewage discharges have led to severe changes in land use pattern in interiors of the lake which is the main source of destruction of natural physiognomies of lake and gradual choking up of its water sources. All this has compounded into complete breakdown of drainage mechanism of the Lake with a threat of floods in Lake Catchment unavoidable in coming time.
\end{abstract}

Keywords: Sewage, Eutrophication, Catchment, Topography, Ecology - ***

\section{INTRODUCTION}

Dal Lake is located close to the east and north of Srinagar city and situated between $74^{\circ} 48^{\prime} / 75^{\circ} 08^{\prime} \& 34^{\circ} 03^{\prime} / 34^{\circ} 13^{\prime}$ at an altitude of 1,583 meters $(5,194 \mathrm{ft})$. It consists of main waterway (Lake) and floating gardens (referred to as "Rad" locally). These floating gardens were and are a major source for supply of fresh vegetables and flowers to Kashmir valley. With an area of 18 square kilometers (6.9 sq mi) without the floating gardens and area of 21.2 square kilometers (8.1 sq mi) including the floating gardens [1]; Dal Lake forms the backbone of ecosystem prevailing in and around the capital city of Srinagar which is also a hub of tourism related activities in state. For its pristine beauty and picturesque landscape Dal has been often referred to as the 'Jewel In the Crown of Kashmir' [2]. To explain the topography of Dal it has been broadly classified into four basins namely Bod Dal, Lakut Dal, Gagribal and Nagin (or Nigeen). The main water sources for the open drainage type lake are the perennial flow Dachigam-Telbal stream and Dara Nallah stream. Apart from this many other small streams joining the lake and over 50 natural underwater springs are sources for feeding fresh water into the lake [1]. The length of the lake is approximately 7.44 kilometers (4.62 mi) with a width of 3.5 kilometers $(2.2 \mathrm{mi})$ and catchment area covering 316 square kilometers (122 sq mi). The lake has a shore length of 15.5 kilometers $(9.6 \mathrm{mi})$ and roads run all along the periphery popularly referred as the Srinagar Boulevard.[3]

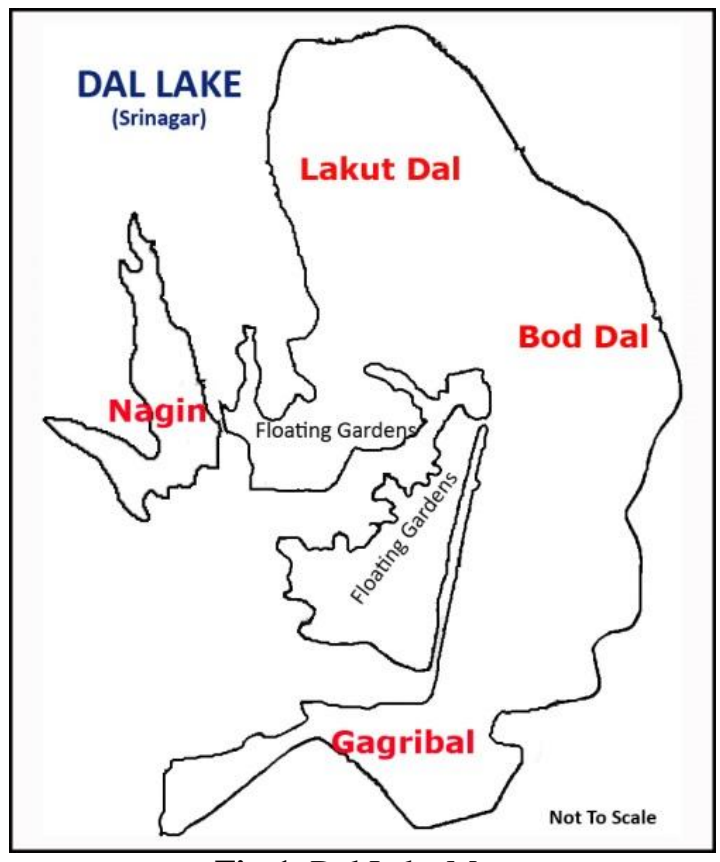

Fig-1: Dal Lake Map

\subsection{Present Scenario \& Difficulties}

The major problem faced by lake is disposal of untreated sewage inside the lake from years at many spots and dismal attitude of locals towards preservation of Lake Environment, 
thus ruining the chemical and biological balance of lake water slowly but steadily. The human excreta and other organic as well as inorganic waste promoting growth of weeds like Typha augustata, Phragmites and many others are largely responsible for slow eutrophication of lake as these form a thick dense blanket of vegetation over water surface making it difficult even for the sunlight to pass through. While the cultivated area within the lake is just 2.29 square kilometers; the area of water body with submerged vegetation is nearly 15.41 square kilometers $(5.91 \mathrm{sq} \mathrm{mi})$ out of the total approximately 21.2 square kilometers (8.1 sq mi) of total lake area. [4]

This uncontrolled vegetation becomes a problem when it is frequently pruned on top but roots are kept intact which tend to become thick over time due to regrowth. This later becomes foundation for setting of new floating gardens by inhabitants which further chokes the free flow of water and gradually increases risk of submerging the city in case of floods.

The floating gardens referred above have been present in the interiors of lake since last century. However the alarming rate of their increasing area due to rising demand and population has been damaging the lake ecosystem badly due to increased emission of nitrogen and phosphorus into lake waters. The floating gardens are formed of weeds collected from the lake itself by local boatmen. The locals collect the weeds and lay their roots into existing undisturbed weeds. This is continued until a dense 2 or 3 layered surface is obtained. Layers of such roots are generally laid one over the other to prepare a garden like patch of nearly 1-2 m depth with water flowing underneath. The roots thus get consolidated into hard material and can hardly be separated. This floating garden with very high amount of nutrients for plants is excellent for speedy growth of vegetables and fruits which ripen well before the suitable time due to highly favorable conditions for rapid growth and nourishment. [5] Over years due to manifold increase in population cultivators have been inclined to increase the area of these floating gardens owing to high agricultural productivity and profits. Thus in an uncontrolled manner they have been resorting to more and more consolidation of roots of aquatic plants for preparation of new such gardens for their business. Additionally growth of trees and other plantation alongside vegetables and fruits has further aggravated the water pollution levels and choked interior natural flow of water within the lake. This shrinkage in lake area and increase in area of floating gardens has posed a serious threat to lake environs. In many instances these gardens which settle down over years into small islands have been used to construct guesthouses which openly discharge their waste directly into the lake. This study shall highlight some of the alarming regions in the Lake interiors whereby conversion of lake way into gardens and subsequently residential huts/ guest houses has been taking place alarmingly and thus making all efforts of authorities to restore splendor of lake into its original form- futile and vague.

\section{MATERIALS/METHODS}

The present investigation has been carried out using satellite images collected using Google Earth (Pro) software system. Satellite images from year 2003 to 2015 have been used extensively used for identification of regions with high rate of conversion of lake ways to land regions and increasing encroachments. Additionally, satellite images of Devastating floods of September' 2014 which hit J\&K state have been used to study water flow pattern and water stagnation data.

The steps involved are-

1. Collection of data using Google Earth Pro Software System on Windows 8.1 (64bit) computer architecture system.

2. Image processing using Adobe PhotoShop CS3 platform.

3. Further color level balancing/corrections using PictoColor software platform.

4. Picture compilation and comparison.

5. Image analysis and deduction of results.

\section{RESULTS \& DISCUSSION}

In order to carry out the analysis, entire lake was classified into four zones based upon rough estimates of levels of encroachment and increase in vegetation. These zones are-

Table-1. Dal Lake zone classification

\begin{tabular}{|l|l|}
\hline ZONE & AREAS OF 'RAD' (Floating Garden) \\
\hline Zone A & Nandpura, Mir Behri \& Malpura \\
\hline Zone B & Karapura and parts of Rainawari \\
\hline Zone C & Ashai Bagh, Kojiarbal \\
\hline Zone D & Inter Lake Road, Mir Behri \& Vic. \\
\hline
\end{tabular}

Figure 1 shows the zoning of Lake with each zone roughly consisting of same area. The regions and areas covered in each zone have been depicted in Table - 1

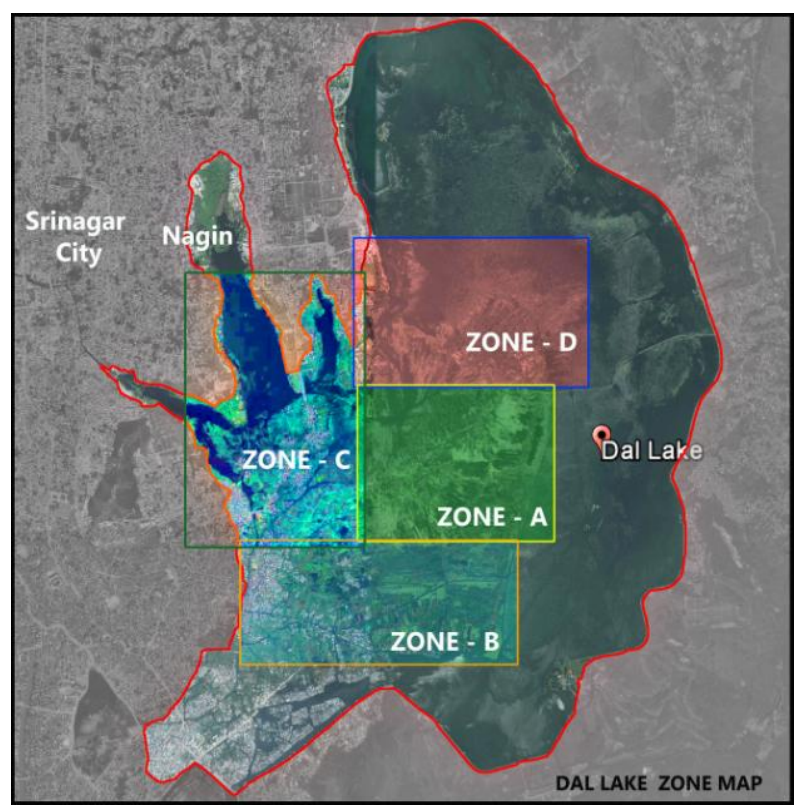

Fig-1: Flow chart of proposed method 


\subsection{Zone-A Analysis}

Regions covered in this zone are by and large the most vulnerable areas and primarily responsible for lake destruction due to agricultural practices. These areas are the original regions of floating gardens that existed without any harm to Lake Environment many decades ago. However this area has experienced maximum changes in terms of conversion of lake to garden as further explained from the comparison data shown in Figure 2. The line passing through the zone and almost dividing the zone into two is the inner lake road that has been now defunct from decades. This road earlier marked the end of gardens towards front of the lake and was being planned as an approach to floating gardens. It is nowadays being used to hold water supply pipes across the lake. The area of gardens or land on right side of road has been drastically increasing due to continuous earth filling and other operations. This can be explained using Figure 3 which shows remarkable increase in cultivated or agricultural land in this zone.

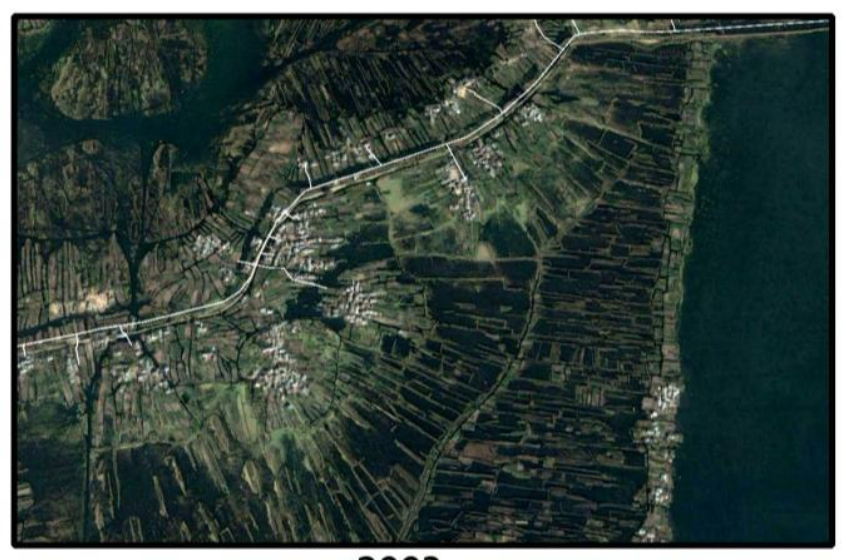

2003

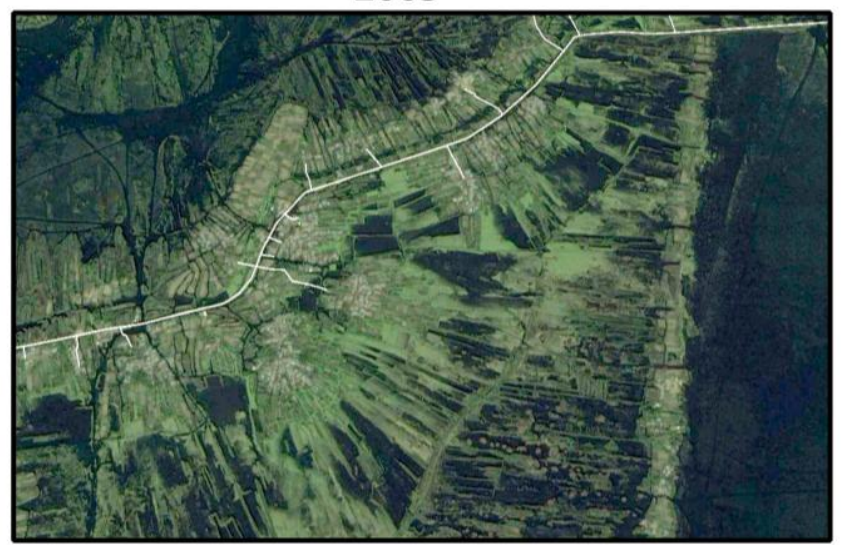

2007

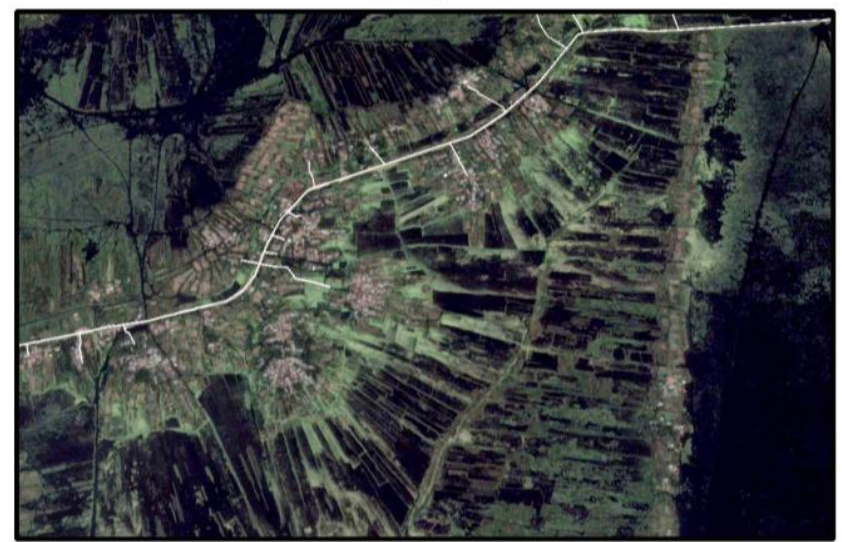

2011

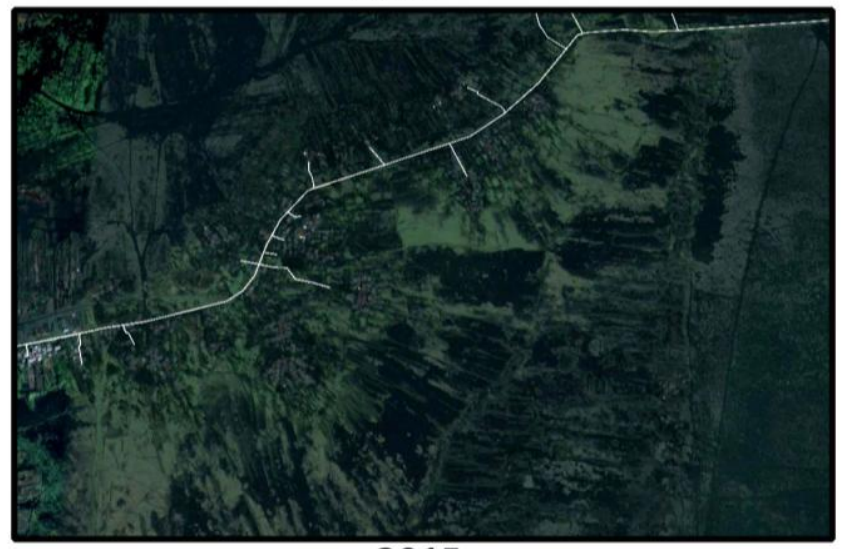

2015

Fig-2: ZONE- A - Lake degradation comparison from 2003 to 2015 


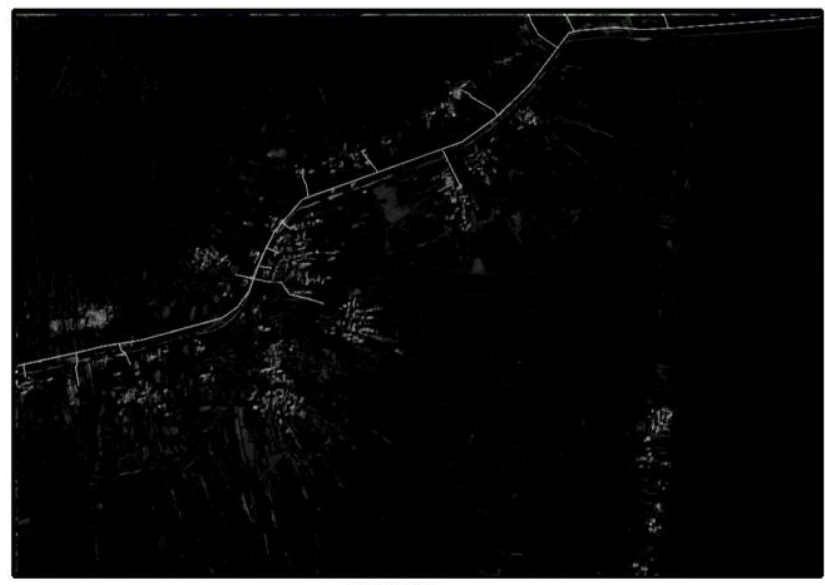

2003

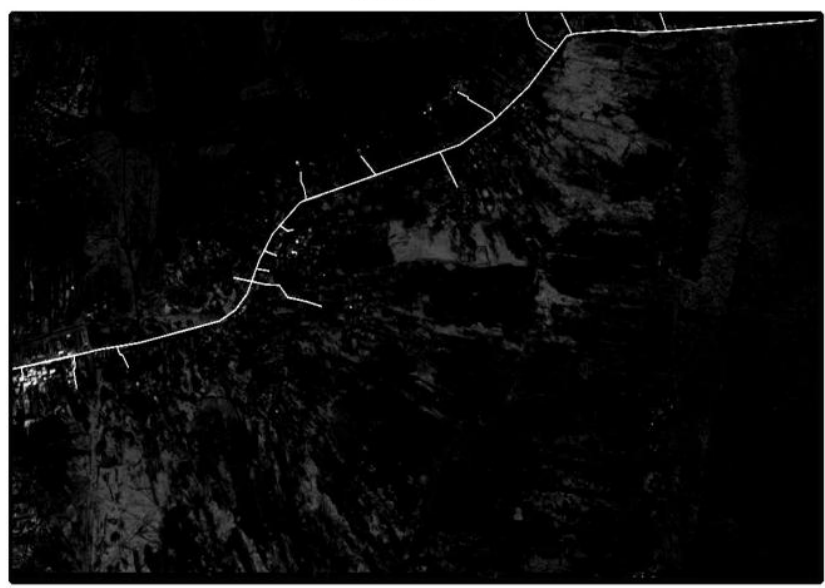

2015

Fig-3 ZONE-A - Graphical gamma variation comparison

\subsection{Zone-B Analysis}

This zone classified on southern part of Lake has witnessed less amount of encroachment on southern end owing to the reason that it is easily accessible to law enforcement agencies. The southern end of this zone consisting of Houseboats for tourist has experienced least encroachment while the central part of the zone has been subjected to large scale changes including development of small hamlets. This zone is also important considering that many sewers open into the lake from left part which is very close to Srinagar city. This zone is also considered as highly polluted region of lake due to continuous discharge of sewage and other untreated waste by Houseboats and Hotels in vicinity directly into the lake. Gamma variation subjected to satellite images (Fig 5) showed significant increase in tin roof sheets mostly used on House boats and Huts towards central part and thus further establishing the above mentioned point.

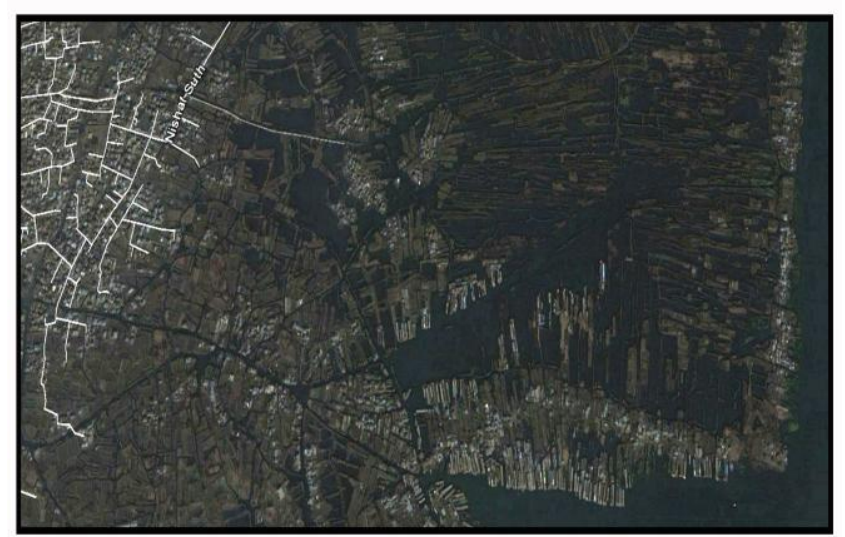

2003

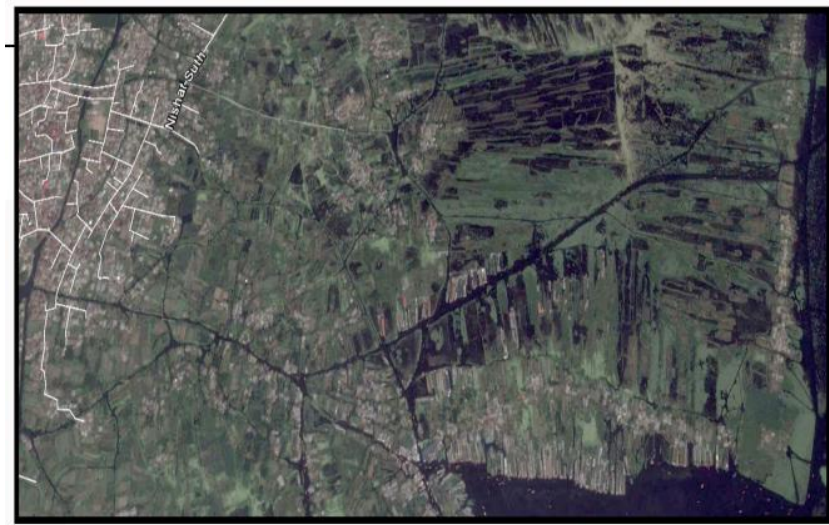

2007

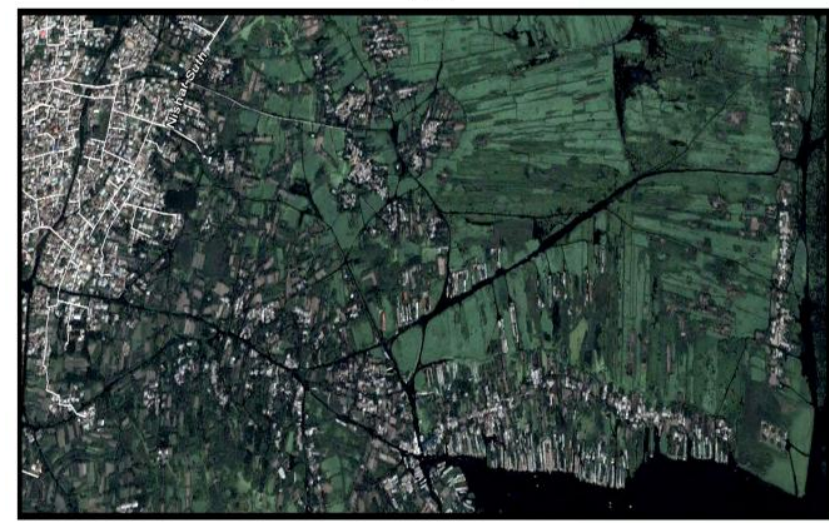

2011

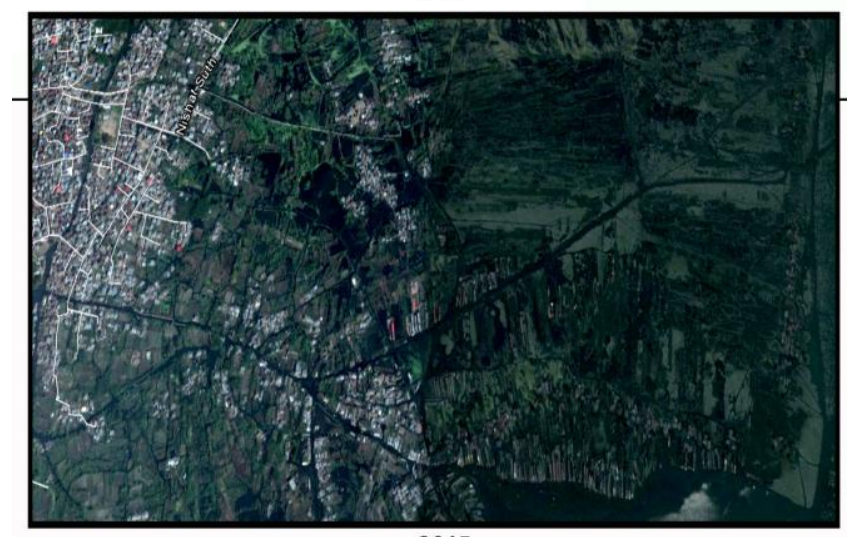

2015

Fig-4: ZONE- B - Lake degradation comparison 


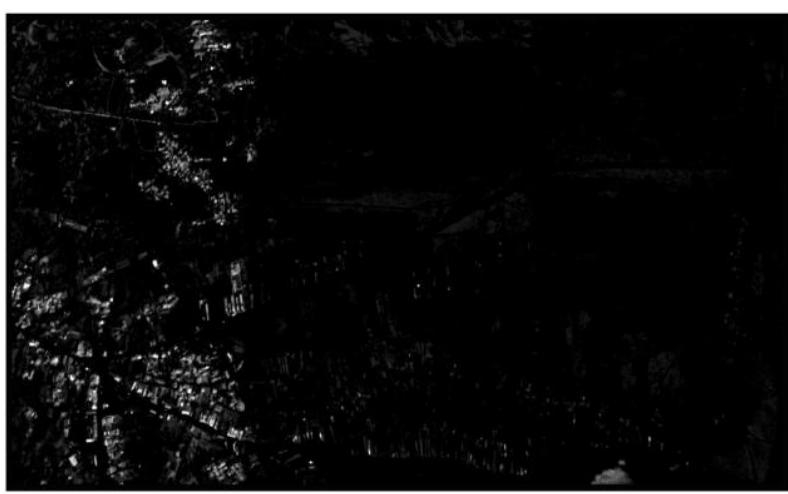

2003

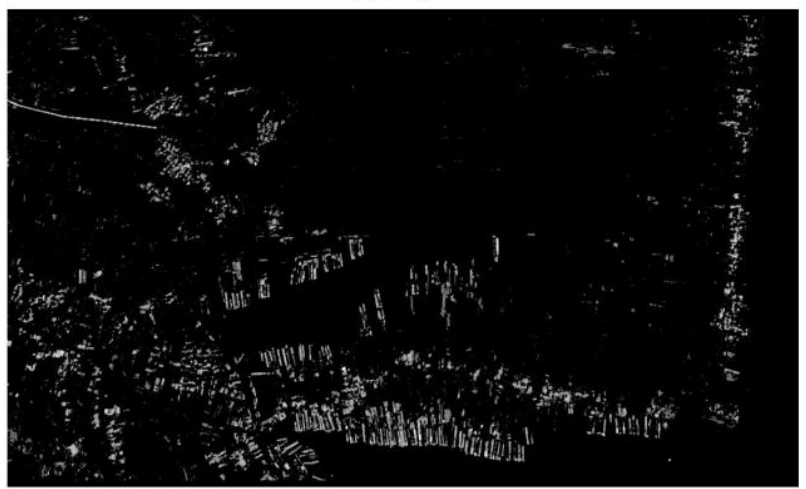

2015

Fig-5: ZONE- B- Graphical gamma variation comparison

\subsection{Zone-C Analysis}

This zone is the worst encroached region of the lake and parts of this region are no longer considered as lake area due to high influence of inhabitants for socio-political reasons that are adamant and claim property rights to the land which actually forms part of Lake Interior on north-west side. Roads have been constructed connecting to schools and colonies developed locally and illegally. This region separates the Nagin (or Nigeen) with main Lake. While the water depth and quality of Nagin is remarkable due to many underwater springs still present; water quality of adjoining Dal is pathetic and largely neglected by lake conservation authorities. Floating markets, guest houses, slums etc. have been developed in this region which is having devastating effect on lake ecology of lake. This region also comprises of many old floating gardens that exist even today and are a major source of fresh vegetables. However, most of the erstwhile gardens have been converted into plots by practicing earth filling and wastage dumping followed by construction of buildings.
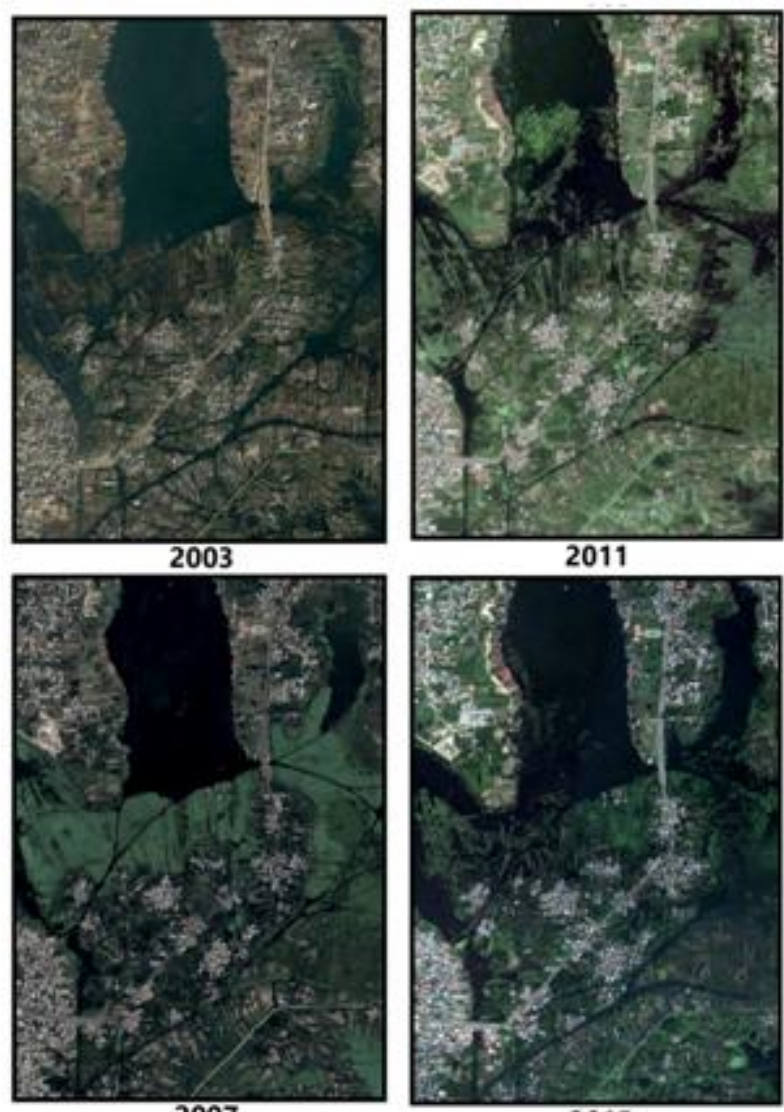

2007

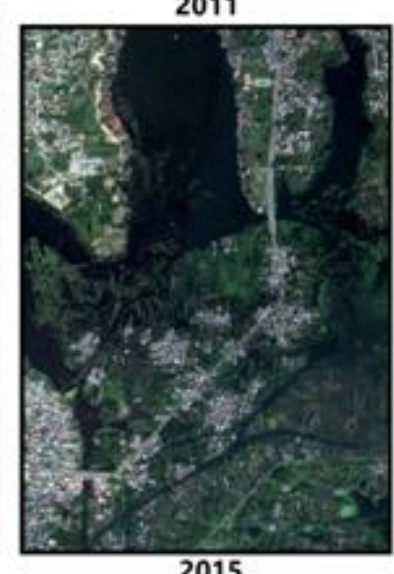

2015

Fig-6: ZONE- C - Lake degradation comparison

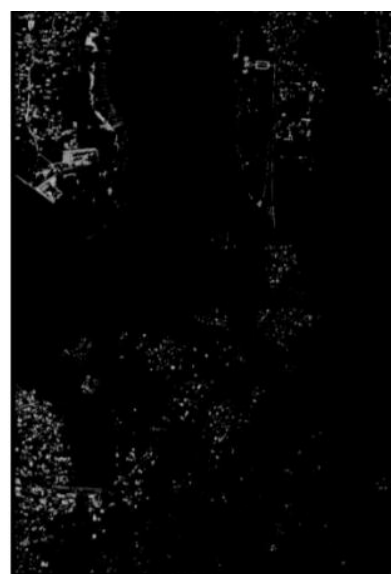

2003

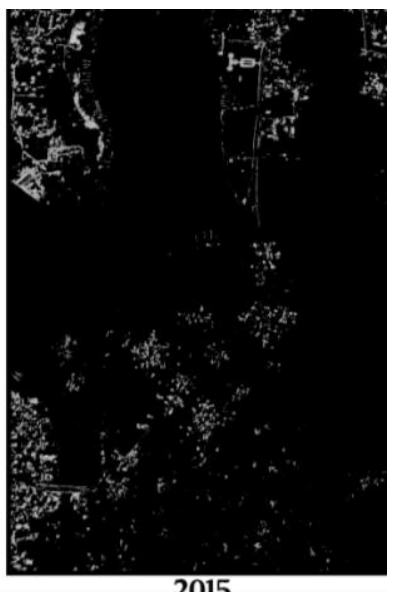

2015
Fig-7: ZONE- C- Graphical gamma variation comparison

\subsection{Zone-D Analysis}

This is the most vulnerable region present in Dal Lake with very small scale encroachments at present from the left end only. This zone is currently being preserved by authorities to its full capability. Though there have been some changes on southern side but nature of such changes is largely negligible. Figure 8 can be referred further to understand the nature of lake in this zone. This zone can thus be considered as best region at the moment existing in lake in terms of water parameters (compared to other zones) and tourism related activities. This is importantly that part of lake which is noticeable from the Srinagar Boulevard. 


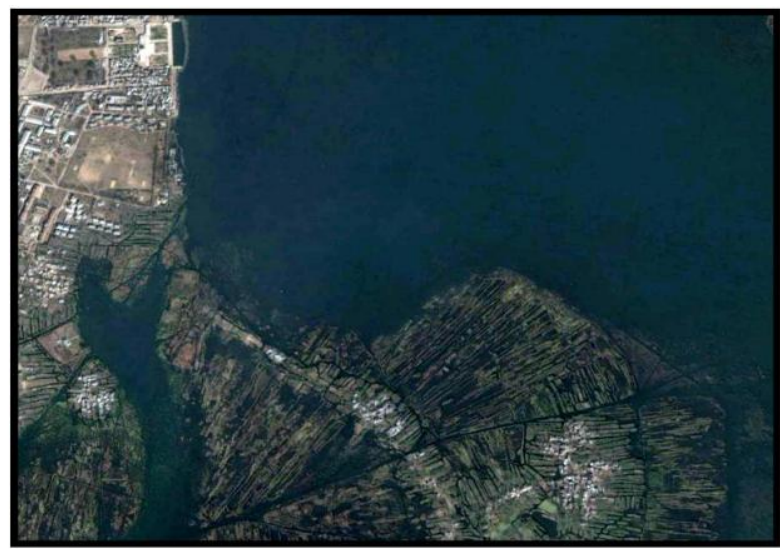

2003

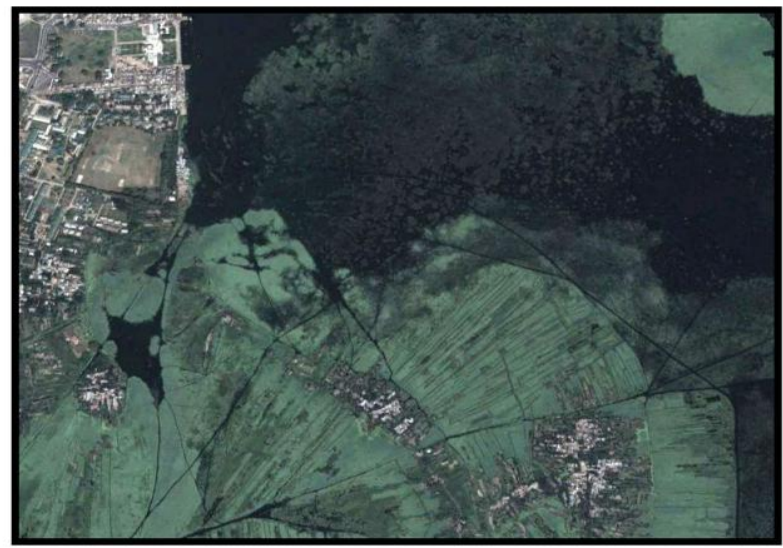

2007

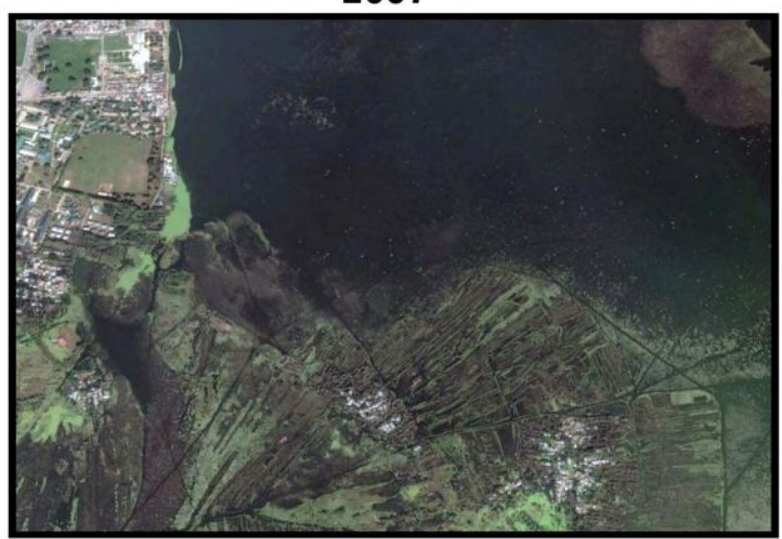

2011

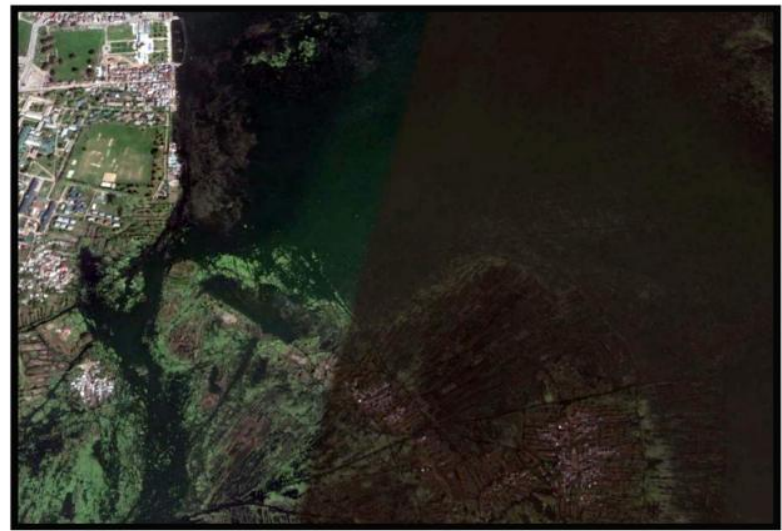

2015

Fig-8: ZONE- D - Lake degradation comparison

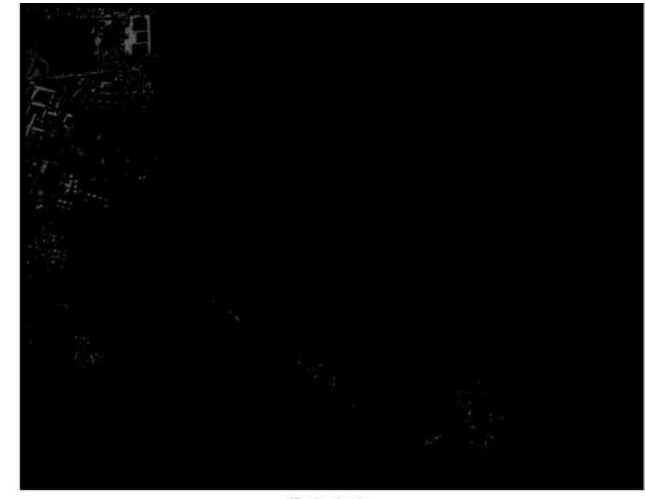

2003

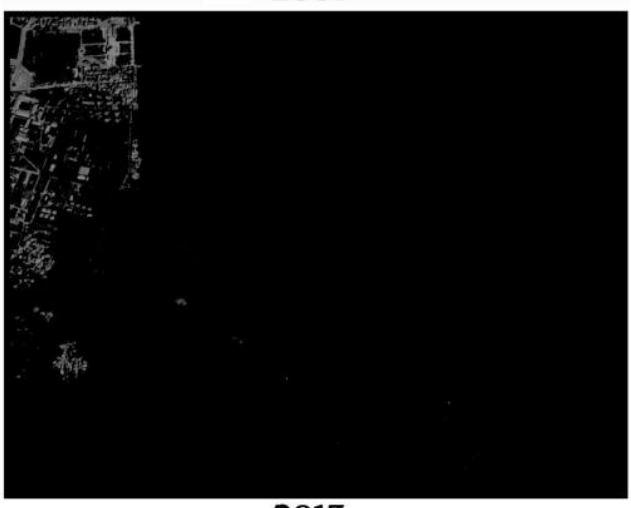

2015

Fig-9: ZONE- D- Graphical gamma variation comparison

\section{FLOOD PARAMETER AND WATER FLOW}

Srinagar city witnessed worst flood in hundred years on 6th September 2014. More than half of capital city of Srinagar was inundated for weeks as most of the rivers and lakes of Kashmir valley were overflowing due to continuous rains and few cloud bursts in hilly areas. The flood data of Dal Lake collected explains complete stagnation in free flow of water in lake due to human interference and uncontrolled exploitation. As explained by Figure 10 Zone A \& B have been completely submerged by flood waters while some portions of Zone $\mathrm{C}$ and almost no part of Zone $\mathrm{D}$ has been effected. The interior flow of water is thus at present expected to be largely inhibited by uncontrolled land filling and unplanned urbanization in lake interior. Due to this immobility of water movement inside the lake famous road along Zone A \& B remained completely submerged for nearly one weak due to flood waters which continued to remain stagnant and had to be ultimately pumped out manually. 


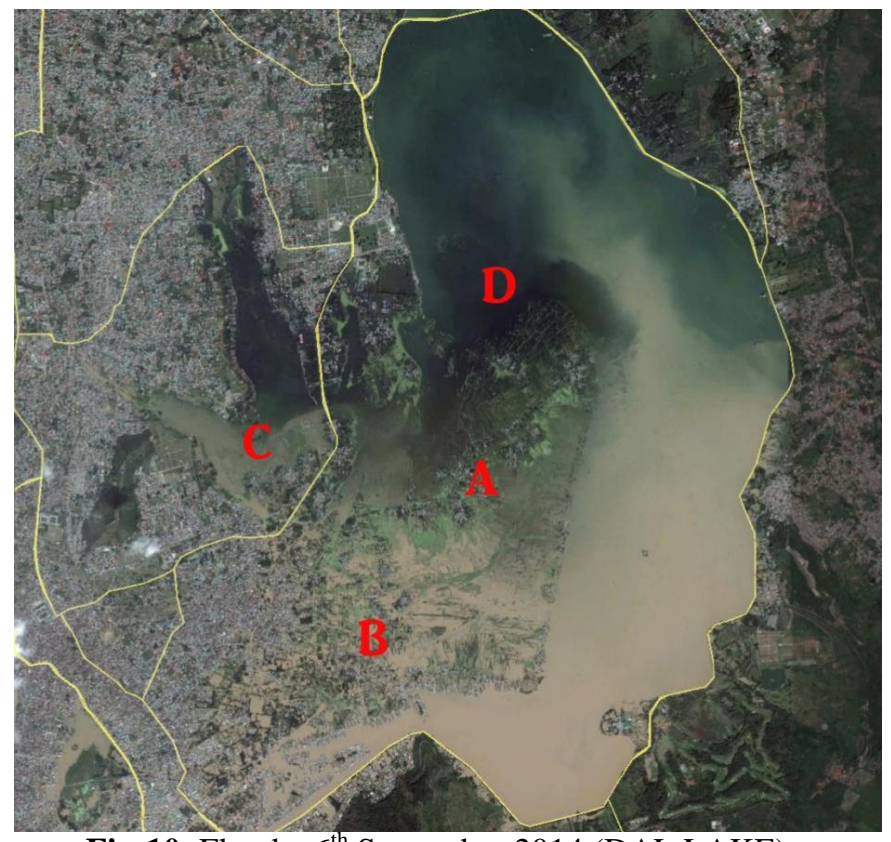

Fig-10: Floods- $6^{\text {th }}$ September 2014 (DAL LAKE)

\section{CONCLUSION}

Dal Lake which was earlier believed to be essential for diverting excess rainfall and avert floods by holding extra water from River Jehlum is no longer in a position to bear extra load as most of the interior channels of water flow in lake have been chocked and blocked. The twelve year data collected enlightens about uncontrolled and unchecked exploitation and encroachments laden with unhealthy practices being adopted by locals to satisfy needs at the cost of environment. In its present form, Dal Lake has turned into a large pool of stinking stagnant sewage water with almost all of its drainage basins clogged and water sources blocked. If no steps are taken to set things right in coming time, Dal Lake poses a serious threat of flooding entire Srinagar city in case of continuous rainfall even for few days.

\section{IMAGES}

1. Google Earth Pro software. Data based on collection from numerous worldwide satellites.

\section{ACKNOWLEDGEMENTS}

The author acknowledges help from friends and family for sharing knowledge and completing this study. Some names to mention include friend Mr. Dhananjay Pandey for technical assistance, Ms Sana and Ms Sania who have always been a source of motivation and encouragement. The author also extends warm regards to Civil Engineering Department (DIT UNIVERSITY) for continuous support and access to necessary equipment and software of institute.

\section{REFRENCES}

[1]. Jain, Sharad K; Pushpendra K. Agarwal; Vijay P. Singh (2007). Hydrology and water resources of India

[2]. Walter Roper Lawrence (1895). The Valley Of Kashmir
[3]. Wikipedia, Dal_lake

[4]. J\&K Lakes \& Waterways Development Authority Website - http://jklda.org

[5]. Prof (Dr.) R.D Gupta. Floating Gardens of Dal Lake. DailyExcelsior.com (2014). 